\title{
Role of adenosine stress perfusion CMR in guiding clinical decision making in pediatric and congenital cardiology: a single pediatric center experience
}

\author{
Hopewell Ntsinjana*, Oliver Tann, Marina Hughes, Silvia Schievano, Vivek Muthurangu, Andrew Taylor \\ From 17th Annual SCMR Scientific Sessions \\ New Orleans, LA, USA. 16-19 January 2014
}

\section{Background}

Compared to adults, coronary artery disease abnormalities, significant enough to warrant viability assessment and adenosine stress perfusion cardiac magnetic resonance (CMR) imaging, are rare in pediatric patients. As a result, the role of adenosine stress perfusion CMR as a routine clinical imaging tool in these patients has not been clearly defined. We aim to evaluate the impact clinically-indicated adenosine stress perfusion CMR on decision-making and follow-up strategy.

\section{Methods}

Medical records and CMR images of all adenosine stress perfusion CMR studies performed on pediatric patients between August 2009 and May 2013 at a single institution were retrospectively reviewed. All examinations were performed on a $1.5 \mathrm{~T}$ Siemens Avanto MRI scanner. Patients $</=10$ years old were examined under general anesthesia. Adenosine stress perfusion CMR protocol included adenosine at $140 \mu \mathrm{g} / \mathrm{kg} / \mathrm{min}$ for a target heat rate increase of $20 \%$ or infusion duration of up to 5 minutes and gadolinium of $0.1 \mathrm{mmol} / \mathrm{kg}$. Institutional review board approved this study and all patients signed informed consent.

\section{Results}

Twenty-seven patients were enrolled (median age 14 years, range 1.4-18.2 years). Twenty-six patients completed the protocol with one study terminated due to extreme chest discomfort and nausea. In all completed studies, a heart rate response of $>20 \%$ was achieved. List of diagnoses and reasons for referral are reported in Table $1.31 \%(8 / 26)$ of the patients had areas of inducible ischemia. Table 2 displays cardiac diagnoses, anatomical lesion on the coronary artery as proven by CMR or subsequent conventional $\mathrm{x}$-ray angiography and clinical decision made after the results of the perfusion study for these patients. Two of the eight patients with areas of inducible ischemia underwent successful revascularisation, and repeat perfusion studies performed after the intervention showed no evidence of inducible ischemia.

\section{Conclusions}

This retrospective study demonstrates that adenosine stress perfusion CMR performed in pediatric patients can positively direct clinical decision-making, Lack of ionising radiation makes this an attractive investigation with which to monitor response to revascularisation.

\section{Funding}

The authors would like to acknowledge the support received from Commonwealth Scholarships, UK National Institute of Health Research (NIHR), Royal Academy of Engineering and EPSRC. This report is independent research by the National Institute for Health Research Biomedical Research Centre Funding Scheme. The views expressed in this publication are those of the authors and not necessarily those of the NHS, the National Institute for Health Research or the Department of Health. 
Table 1 Cardiac diagnosis and reason for referral.

\begin{tabular}{ccc}
\hline Cardiac diagnosis & $\mathbf{N}$ & Reason for Referral (n) \\
\hline ALCAPA post Coronary re-implantation & 6 & $\begin{array}{c}\text { Chest pain (3) } \\
\text { Routine (3) }\end{array}$ \\
\hline Kawasaki disease & 6 & Abnormal echocardiogram (6) \\
\hline Transposition of Great arteries post arterial switch & 4 & $\begin{array}{c}\text { Chest pain (3) } \\
\text { Abnormal EKG on exercise (1) }\end{array}$ \\
\hline Dilated Cardiomyopathy & 3 & $\begin{array}{c}\text { Abnormal EKG (2) } \\
\text { Abnormal echocardiogram (1) }\end{array}$ \\
\hline Homozygous familial hypercholesterolemia & Clinician's request (2) \\
\hline Atretic left anterior descending coronary artery & 2 & Sudden collapse during exercise \\
\hline Bicuspid aortic valve & 1 & Dyspnea on exercise \\
\hline Dodtic stenosis post Ross procedure & 1 & Chest pain \\
\hline DORV post repair & 1 & Chest pain \\
\hline Takayasu's arteritis & 1 & Chest pain
\end{tabular}

ALCAPA (Anomalous left coronary artery from pulmonary artery), EKG (Electrocardiogram), DORV (Double outlet right ventricle)

Table 2 Clinical Outcome of Positive Stress Test.

\begin{tabular}{|c|c|c|c|c|}
\hline Patient & $\begin{array}{c}\text { Age } \\
\text { (years) }\end{array}$ & Cardiac diagnosis & Anatomical coronary lesion & Clinical decision \\
\hline 1 & 9 years & ALCAPA post repair & $\begin{array}{l}\text { Focal stenosis of re-implanted left main } \\
\text { coronary artery }\end{array}$ & Plan for surgical re-vascularization \\
\hline 2 & 14 years & TGA post ASO & Mild ostial stenosis of left main & Limit strenuous exercise \\
\hline 3 & 10 years & Kawasaki & Aneurysmal left main stem & Medical therapy \\
\hline 4 & 10 years & Kawasaki & Left main stem stenosis & Endovascular coronary stent implantation \\
\hline 5 & 15 years & Kawasaki & Aneurysmal LAD & Medical therapy \\
\hline 6 & 18 years & ALCAPA post repair & Not detected & Plan for coronary angiography \\
\hline 7 & 12 years & ALCAPA post repair & $\begin{array}{c}\text { Focal stenosis of re-implanted left main } \\
\text { coronary artery }\end{array}$ & $\begin{array}{c}\text { After x-ray angiography increased follow-up } \\
\text { surveillance }\end{array}$ \\
\hline 8 & 14 years & $\begin{array}{c}\text { Takayasu's arteritis previous } \\
\text { LIMA graft }\end{array}$ & Obstructed LIMA graft & Exercise testing \\
\hline
\end{tabular}

ALCAPA (Anomalous left coronary artery from pulmonary artery), TGA (Transposition of great arteries), ASO (Arterial switch operation), LAD (Left anterior descending artery), LIMA (Left internal mammary artery).

Published: 16 January 2014

doi:10.1186/1532-429X-16-S1-P128

Cite this article as: Ntsinjana et al:: Role of adenosine stress perfusion CMR in guiding clinical decision making in pediatric and congenital

cardiology: a single pediatric center experience. Journal of Cardiovascular Magnetic Resonance 2014 16(Suppl 1):P128.

\section{Submit your next manuscript to BioMed Central} and take full advantage of:

- Convenient online submission

- Thorough peer review

- No space constraints or color figure charges

- Immediate publication on acceptance

- Inclusion in PubMed, CAS, Scopus and Google Scholar

- Research which is freely available for redistribution

Submit your manuscript at www.biomedcentral.com/submit 